\title{
Interactive comment on "A new approach for modeling suspended sediment: Evolutionary fuzzy approach" by O. Kisi
}

\section{Anonymous Referee \#2}

Received and published: 14 July 2016

In this manuscripts, the evolutionary fuzzy (EF) approach was applied for prediction of daily suspended sediment concentration (SSC). The EF was improved by the combination of two methods, fuzzy logic and genetic algorithm. The accuracy of EF models is compared with those of the artificial neural network (ANN) and adaptive neuro-fuzzy inference system with fuzzy c-means clustering (ANFIS-FCM). The daily streamflow and suspended sediment data collected from two stations on the Eel River in California, United States are used in the study. Comparison of the optimal EF, ANN and ANFIS-FCM models in estimating peak and total suspended sediments revealed that the EF model provided better accuracy than the ANN and ANFIS-FCM. The study technically sounds and is generally well written. However, there are some points that should be considered in the revised paper before its publication. The literature section should be re-organized by removing some of excessive references (e.g., self-citations). 
Dates of the references are not new and do not seem to be up to date. Some recently published papers should be added in to the literature. The methods section needs extension. The ANN and ANFIS are missing in the methods section and they should be briefly explained. Which type of fuzzy system did you use in EF method? This should be clearly provided. Consequent parameters and rules of the optimal EF and ANFIS models should be provided. How the author find optimal hidden node of the ANN models? This can be explained by giving error variation with respect to hidden node number. The membership functions may be provided for the optimal models. The results obtained from the study may be compared with previous ones related to same topic. Future studies section may be added at the end of the Conclusions section.

Interactive comment on Hydrol. Earth Syst. Sci. Discuss., doi:10.5194/hess-2016-213, 2016. 